\title{
Understanding Homelessness: A Call to Action and Curriculum Framework for Psychiatry Residencies
}

\author{
Elizabeth M. Moore ${ }^{1}$ (D) $\cdot$ Theresa H. Cheng ${ }^{2}$ - Enrico G. Castillo ${ }^{3} \cdot$ Lillian Gelberg $^{1} \cdot$ Roya ljadi-Maghsoodi $^{4}$
}

Received: 12 March 2019 / Accepted: 25 November 2019 / Published online: 2 January 2020

(C) Academic Psychiatry 2020

Homelessness is a critical public health issue that disproportionately affects those with mental illness [1,2]. The 2018 point-intime count of homelessness on a given night found that 552,830 people were experiencing homelessness [3]. The total number of people experiencing homelessness over the course of a given year is difficult to evaluate but was estimated at 2.3 to 3.5 million in 2000 [4]. While homelessness nationally has declined over the last decade, it has grown in 12 states and has increased sharply in some regions [5]. Over the past 2 years in California, for instance, homelessness increased $17 \%$ in San Francisco, 42\% in Alameda, and 43\% in Orange County [6]. In Los Angeles, homelessness and deaths among those who are homeless have increased in recent years [7], leading public officials to label it a public health crisis [8]. Even in regions with declining rates of homelessness, issues such as housing insecurity, falling into homelessness due to economic shocks, or doubled-up living arrangements may be relevant [9].

Given the high rates of mental illness among individuals experiencing homelessness $[10,11]$, psychiatry residents are likely to treat patients who are homeless, even in regions that are not experiencing rising homelessness. The clinical skills and knowledge necessary to care for patients experiencing homelessness go beyond the skills acquired during more broad public psychiatry training. Despite the Accreditation Council for Graduate Medical Education (ACGME) Milestones in psychiatry focused on community-based care [12], only $60 \%$ of programs provide education related to

Elizabeth M. Moore

emmoore@mednet.ucla.edu

1 VA Greater Los Angeles Health System, Los Angeles, CA, USA

2 UCLA Health System, Los Angeles, CA, USA

3 Los Angeles County Department of Mental Health, Los Angeles, CA, USA

4 Jane and Terry Semel Institute for Neuroscience \& Human Behavior at UCLA, Los Angeles, CA, USA homelessness, and only $11 \%$ include required clinical rotations focused on homelessness [13].

A case study by Braslow and Messac [14] published in 2018 in the New England Journal of Medicine describes a common scenario during psychiatry residency. The authors describe a patient with chronic homelessness who presents to an emergency department (ED) exhibiting psychotic symptoms and requesting help. The treating psychiatry resident finds on review of the patient's medical record that he frequently comes to the ED with similar complaints, so she decides to discharge the patient. The authors describe a dismal outcome for the patient-he is currently in jail pending trial for felony charges.

In cases like these, there are clinical skills and interventions that can be taught during residency that can result in improved outcomes. In this article, we review the literature on mental illness in people experiencing homelessness. We then review the current state of psychiatry residency program education surrounding homelessness. Finally, we propose a set of educational goals and didactics focused on homelessness for psychiatry residency training programs. For programs without the capacity to implement a new set of didactics, we have also included strategies for programs to incorporate education in homelessness into existing didactics. We hope this article underscores the importance of homelessness education within psychiatry training programs, and serves to call residency directors to action to ensure that future psychiatrists are equipped to care for this important population.

\section{Increased Risks of Mental Illness and Environmental Stress During Homelessness}

The mental health field has an important role and long history in leading strategies to address homelessness. Among homeless populations, $28 \%$ suffer from chronic mental illness [15]. The prevalence of schizophrenia among people who are 
homeless is estimated to be between 4.4 and $16 \%$ [16], and that of major depression is estimated at $11.4 \%$ [17]. People who are homeless are also at serious risk of suicide: a study of individuals with serious mental illness experiencing homelessness found that $37.5 \%$ had reported suicidal thoughts in the previous month, and over half reported at least one lifetime suicide attempt (8\% within the last month) [18].

Substance use disorders (SUDs) are also prevalent among people who are homeless in the USA (30-49\%) [15], with serious consequences: drug overdose is the leading cause of death among people who are homeless [19]. A study of ED patients found higher rates of alcohol misuse, binge drinking, and illicit drug use among those experiencing homelessness compared with those who were housed [20]. Qualitative studies of older adults experiencing homelessness describe substance use as a means to cope with physical pain or mental distress [21]. Numerous studies have described barriers to access to mental and behavioral health services for people experiencing homelessness [22], despite provisions in the Affordable Care Act defining substance use treatment as an essential health benefit [23] and the Mental Health Parity and Addiction Equity Act of 2008 (MHPAEA) [24].

It is also important to appreciate the unique stressors of homelessness, given that they extend beyond the stressors of living in poverty while housed. A patient that lives in poverty but has stable housing may experience food insecurity, poor health, and crime. However, a loss of housing leaves patients vulnerable to a worsening of all of these circumstances. They may additionally become isolated from their communities, and perhaps lose employment and sense of purpose. Some patients experiencing homelessness endure an increased risk of violence [25] and may be forced to engage in survival sexthat is, trading sex for basic needs like housing and food [26]. Patients without housing may forgo medical and psychiatric care due to competing priorities or may be hesitant to take sedating night-time medications due to safety concerns while sleeping in unsecured locations. These stressors can impact both mental and physical health.

\section{The Current State of Homelessness Education Within Psychiatry Residency Training}

While any psychiatrist can work with people who are experiencing homelessness, specialized training can help develop the most effective clinicians, researchers, and advocates for these patients. Several educational approaches might include homelessness within psychiatry residency programs. Public psychiatry focuses on publicly funded, under-resourced populations and services. Public psychiatry training experiences provide residents with early exposure to specialized multidisciplinary services for marginalized populations. Examples relevant to homelessness include street psychiatry rotations at the University of North
Carolina [27] and Brown University [27, 28] and an outpatient elective at the Interprofessional Academic Homeless Patient Aligned Care Team (HPACT) at the West Los Angeles VA [29].

Residents can also learn about homelessness by fulfilling the ACGME educational competency for systems-based practice. Educators have adapted this competency to teach residents to leverage health care and other system-level resources for the benefit of patients. A systems-based practice educational intervention, for example, might include a resident quality improvement project to implement a patient screener for housing status $[20,23]$.

Residency programs may also offer training in structural competency, which urges an awareness of the structures that influence health, such as housing and zoning policies [30]. A structural competency approach to homelessness might encourage advocacy to increase local funding for evidence-based supportive housing or communityacademic partnerships to better meet the social needs of those patients experiencing homelessness [30]. Systemsbased practice and structural competency curricula are emerging in psychiatry training programs, including Yale [31], UCLA [32], NYU [33], Columbia [34], and the University of California-Davis [35].

\section{Proposed Residency Curriculum in Homelessness: Educational Goals}

We propose four resident educational goals and additional specific didactics to guide programs' development of curricula in homelessness (Table 1). These goals and didactics are compatible with existing educational approaches in public psychiatry, systems-based practice, and structural psychiatry. For programs that do not have the resources or room in their didactic schedules to add a new curriculum on homelessness, we have included suggestions to facilitate implementation of homelessness education into existing didactics (Table 2).

\section{Goal 1}

The first goal for resident education is to evaluate patients, including special populations, for housing status and relevant social determinants of health. Understanding the social determinants of health for patients who are homeless will help residents provide sensitive, collaborative, and effective healthcare $[29,36]$. Homelessness is a potent social determinant of health. Life expectancy among those experiencing homelessness is greatly reduced, estimated to be $43-$ 47 years of age [37]. People who are homeless are less likely than the general population to get medical care from a primary care doctor [38]; they may have difficulty keeping appointments and proving insurance status or may have negative experiences with health care [39]. In the face of resource 
Table 1 Psychiatry residency curriculum in homelessness. We have proposed four educational goals in homelessness for psychiatry residents. All educational goals are relevant to ACGME competencies. The table also provides guidance on necessary resources

\begin{tabular}{|c|c|c|c|c|}
\hline & Proposed didactic & Instructor & $\begin{array}{l}\text { Time } \\
\text { required }\end{array}$ & Relevant ACGME competencies \\
\hline $\begin{array}{l}\text { Educational goal 1: Evaluate } \\
\text { patients, including special } \\
\text { populations, for housing status } \\
\text { and relevant social } \\
\text { determinants of health. }\end{array}$ & $\begin{array}{l}\text { Overview of social determinants of } \\
\text { health for people who are homeless, } \\
\text { including the impact on health of a } \\
\text { patient's housing status, use of } \\
\text { shelters, and use of relevant } \\
\text { resources. } \\
\text { Overview of ACES and TIC }\end{array}$ & $\begin{array}{l}\text { Social worker or } \\
\text { psychiatrist with } \\
\text { experience } \\
\text { working with } \\
\text { homeless } \\
\text { populations } \\
\text { Child psychiatrist, } \\
\text { pediatrician, social } \\
\text { worker, or } \\
\text { psychologist }\end{array}$ & $1 \mathrm{~h}$ & $\begin{array}{l}\text { IV.A.5.a).(1). (b).(vi) demonstrate } \\
\text { competence in formulating an } \\
\text { understanding of a patient's } \\
\text { biological, psychological, } \\
\text { behavioral, and sociocultural issues } \\
\text { associated with etiology and } \\
\text { treatment. } \\
\text { IV.A.5.d).(1) communicate effectively } \\
\text { with patients, families, and the } \\
\text { public, as appropriate, across a broad } \\
\text { range of socioeconomic and cultural } \\
\text { backgrounds }\end{array}$ \\
\hline $\begin{array}{l}\text { Educational goal 2: Understand } \\
\text { appropriate referrals to } \\
\text { evidence-based care models for } \\
\text { patients experiencing } \\
\text { homelessness. }\end{array}$ & $\begin{array}{l}\text { Overview of local community } \\
\text { healthcare resources for people } \\
\text { experiencing homelessness and } \\
\text { mental illness. } \\
\text { Overview of the benefits of Assertive } \\
\text { Community Treatment (ACT) for } \\
\text { patients experiencing homelessness. }\end{array}$ & $\begin{array}{l}\text { Social worker, case } \\
\text { manager, or } \\
\text { community leader } \\
\text { ACT administrator }\end{array}$ & $1 \mathrm{~h}$ & $\begin{array}{l}\text { IV.A.6.a).(14) Resident experience in } \\
\text { community psychiatry must provide } \\
\text { residents with a cohort of persistently } \\
\text { and chronically ill patients in the } \\
\text { public sector (a) This experience } \\
\text { must include learning about and } \\
\text { using community resources and } \\
\text { services }\end{array}$ \\
\hline $\begin{array}{l}\text { Educational goal 3: Analyze } \\
\text { structures that impact housing, } \\
\text { and advocate to improve health } \\
\text { of people who are homeless. }\end{array}$ & $\begin{array}{l}\text { Overview of low-income housing and } \\
\text { rapid re-housing programs in the } \\
\text { community. } \\
\text { Analyzing the causes and consequences } \\
\text { of homelessness, and advocating } \\
\text { effectively for structural change. } \\
\text { Overview of medical-legal } \\
\text { partnerships. }\end{array}$ & $\begin{array}{l}\text { Community leader } \\
\text { Attorney with } \\
\text { expertise in this } \\
\text { area }\end{array}$ & $1 \mathrm{~h}$ & $\begin{array}{l}\text { IV.A.5.f) Residents must demonstrate } \\
\text { an awareness of and responsiveness } \\
\text { to the larger context and system of } \\
\text { healthcare, as well as the ability to } \\
\text { call effectively on other resources in } \\
\text { the system to provide optimal } \\
\text { healthcare. } \\
\text { IV.A.5.f).(4) Residents are expected to } \\
\text { advocate for quality patient care and } \\
\text { optimal patient care systems. }\end{array}$ \\
\hline $\begin{array}{l}\text { Educational goal 4: Exhibit } \\
\text { humanism when interacting } \\
\text { with patients experiencing } \\
\text { homelessness. }\end{array}$ & $\begin{array}{l}\text { Humanistic clinical interactions: How } \\
\text { to obtain a narrative history from a } \\
\text { patient experiencing homelessness; } \\
\text { investigating personal subjective } \\
\text { reactions to homelessness (e.g., } \\
\text { cynicism, lack of self-efficacy, bias) }\end{array}$ & $\begin{array}{l}\text { Social worker, } \\
\text { psychiatrist, } \\
\text { psychologist, or } \\
\text { chief resident }\end{array}$ & $1 \mathrm{~h}$ & $\begin{array}{l}\text { IV.A.5.e).(5) Residents are expected to } \\
\text { demonstrate sensitivity and } \\
\text { responsiveness to a diverse patient } \\
\text { population, including but not limited } \\
\text { to diversity in gender, age, culture, } \\
\text { race, religion, disabilities, and sexual } \\
\text { orientation. }\end{array}$ \\
\hline
\end{tabular}

scarcity, people experiencing homelessness make individuallevel tradeoffs in favor of necessities like food or shelter over health care services, contributing to downstream delays in preventive care and overutilization of acute care services [40, 41]. Residents may need to develop trust and rapport with these patients before they agree to start psychiatric treatment; they may first need to assist their patients with housing or employment needs.

Some subgroups of patients have unique social determinants that residents should recognize. Children are impacted significantly by housing instability, parental substance use and mental health problems, poverty, and witnessed violence. Many of these experiences are considered adverse childhood experiences (ACEs) and are known to affect health. These children have increased risk of academic problems, mental health problems, developmental delay, cognitive outcomes, and homelessness in the future $[42,43]$.

Residents should also be aware of the social determinants of health among women who experience homelessness. Domestic violence is the leading cause of homelessness for women [44], and a study of mothers who were homeless found that $93 \%$ had experienced trauma [45]. They may be at continued risk for sexual victimization because they may engage in survival sex for basic needs; they are also at risk for sexually transmitted infections [46-48].

Finally, veterans experiencing homelessness have unique social determinants and resources. Veterans are more likely than the general population to be homeless; beyond general risk factors like poverty, they may have 
Table 2 Adding homelessness education to existing didactics. Some programs do not have the resources or capacity to add an additional homelessness curriculum. These programs can incorporate educational material on homelessness into existing didactics, case conferences, and clinical experiences for residents. These programs may also benefit from the listed additional resources on homelessness

Opportunities for programs to incorporate homelessness into existing curricula

Educational goal 1

Educational goal 2

Educational goal 3

Educational goal 4

Additional resources

-National Center on Homelessness Among Veterans: https://www.va.gov/homeless/nchav/index.asp and Veterans Affairs Housing Toolkit: https://www.va.gov/homeless/docs/toolkit/DigitalHousingBody102715_508.pdf

-SAMHSA Homelessness Programs and Resources: https://www.samhsa.gov/homelessness-programs-resources

-Trauma and Resiliency-Informed Care Toolkit: https://www.downtownwomenscenter.

org/wp-content/uploads/2018/12/Trauma-and-Resiliency-Informed-Care-Toolkit-updated-12.10.18.pdf

-National Health Care for the Homeless Council: https://nhchc.org/

also experienced military trauma, traumatic brain injury, and difficulty adjusting to life outside of the military [49]. Conditions such as posttraumatic stress disorder and military sexual trauma may increase the risk of homelessness among veterans $[50,51]$. Women veterans experiencing homelessness may be especially vulnerable to a loss of social connections; indeed, women veterans are four times as likely to be homeless than civilian women [50, 52].

Given the high prevalence of trauma during periods of homelessness, individuals experiencing homelessnessespecially vulnerable populations such as women, children, and veterans - are at risk for re-traumatization in health care settings. These patients may benefit when residents employ a trauma-informed approach to care [53]. Trauma-informed care refers to a set of principles that guide treatment - such as collaboration, trust, empowerment, and safety - with the goal of avoiding distress and re-traumatization $[53,54]$. Residents can offer opportunities for patients to rebuild control, at least during the clinical encounter; ensure environmental and emotional safety; and utilize a strengths-based approach to care.

Table 1 identifies two resident lectures on providing compassionate care to homeless persons. The first provides an overview of the social determinants of health for subgroups of people experiencing homelessness; the second focuses on trauma-informed care, ACEs, and adult victimization. Programs in cities with a high burden of homelessness may consider adding lectures focused on unmet health care needs among people who are homeless and the unique impact of homelessness among veterans. Programs with less flexibility in their curricula can consider including cases on homelessness in existing case conferences. They can also include trauma-informed care in their existing lectures on highrisk populations or on lectures about trauma (Table 2).

\section{Goal 2}

The second goal for resident education is to understand and practice appropriate referrals to evidence-based health care models for patients experiencing homelessness. Patients who are homeless benefit from health care that is tailored to their needs. Residents who are educated on these models will understand the core components and benefits of these programs and will be empowered to practice appropriate referrals to programs that are available in their communities. If such programs are not available in their communities, education on evidence-based models may inspire resident advocacy for such programs. One example is the US Health Care for the Homeless Program (HCHP), a delivery model that includes comprehensive primary care, substance use treatment, and supportive services. The HCHP became a national program in 1987, and today 285 HCHPs are located across the country. The Boston Health Care for Homeless Program (BHCHP) serves over 12,000 people who are homeless in Boston, MA. Its team of outreach providers sees patients in shelters and the streets in an attempt to overcome barriers of transport, property, and stigma in the clinic setting [55].

Another delivery model that is well suited to the care of patients who are homeless is the patient-centered medical home (PCMH), which is a physician-directed care setting that provides coordinated and continuous care [56]. The Veterans' Administration uses a PCMH model called the Homeless 
Patient-Aligned Care Team (HPACT), created to provide social services, primary care, and mental health care to veterans who are homeless. HPACT emphasizes using an empathic approach with patients that is cognizant of their barriers to care. For instance, HPACT tries to accommodate walk-ins whenever possible. Six months after implementation of HPACT, emergency department visits decreased by $19 \%$ and hospitalizations by $34 \%$ [29].

Assertive Community Treatment (ACT) programs also serve people with severe mental illness and have demonstrated improvements in symptoms and housing status among homeless populations [57]. These programs conduct longitudinal outreach services to people who are homeless and provide intensive case management and social work in addition to mental health treatment. ACT is well studied and associated with lower rates of psychiatric hospitalization and increased housing stability [57].

Table 1 includes two didactic sessions to help residency programs fulfill this educational goal. The didactics we suggest are an overview of community resources and local delivery models and an overview of ACT programs. These sessions can be led by experienced psychiatrists, social workers, or administrators within these care settings. A relevant clinical experience could consist simply of practicing appropriate referrals under the guidance of a knowledgeable clinician, or even of a rotation at a specialized care model or ACT program if this is possible. Programs with less flexibility in their curricula can focus on encouraging appropriate referrals from the inpatient unit or ED (Table 2).

\section{Goal 3}

The third goal for resident education is to analyze structures that impact housing and to advocate to improve the health of people who are homeless. More broadly, it is helpful for psychiatry residents to understand existing structures that impact homelessness, which can include economic policies, historic practices such as redlining, and current issues such as lack of rent stabilization or other tenant protections, immigration policies and patterns, racism, stigma, and the criminal justice system. Psychiatrists have the opportunity to advocate on behalf of patients experiencing homelessness. In some systems, psychiatrists have specific gatekeeper functions and can help patients secure treatment services, for example, with finances (such as disability benefits) and diversion from incarceration, both of which can relate to homelessness prevention. Psychiatrists can also conduct housing evaluations, which are essential components of patients' applications (e.g., HRA 2010e) for permanent supportive housing, such as in New York City's NY/NY III housing system [58]. At UCLA's psychiatry residency, a core curriculum class was developed on homelessness policies (Measures $\mathrm{H}$ and $\mathrm{HHH}$ ) and roles for psychiatrists within local initiatives [59]. The class is taught by a local policymaker.
Cities are starting to implement novel policies to prevent and end homelessness. Measure H in Los Angeles County appropriates $\$ 40$ million to such assistance; funds can be used to cover rent or moving expenses for people who may otherwise become homeless [59]. Residents should be aware of lowincome housing, Housing First [60], and rapid re-housing programs [61] in their regions such as Section 8 housing vouchers [62], Housing Opportunities for Persons with AIDS (HOPWA) [63], Public Housing, the Low-Income Housing Tax Credit program [64], and other housing available for special populations such as seniors or persons with disabilities.

For veterans in particular, a cornerstone of the effort to end veteran homelessness is a partnership between the US Department of Housing and Urban Development and VA Supportive Housing (HUD-VASH) [65]. This program is a component of the Section 8 Housing Choice Voucher (HCV) program for civilians. Like all HCV vouchers, HUD-VASH vouchers are exchanged for private rentals. They are allocated specifically for veterans, and the program includes additional funding to the VA for case management services [65]. In 2018, in addition to renewing existing housing vouchers, the government appropriated $\$ 40$ million specifically to new vouchers for the HUD-VASH program [66]. Typically, veterans can be assessed for homelessness at VA facilities and then referred to housing agencies for vouchers.

Residents can learn how to refer and advocate for their patients through collaborations with local medical-legal partnerships, in which legal experts work together with health care providers to aid patients who are homeless or with local legal aid organizations specializing in housing and eviction defense [67]. Through this cross-sector collaboration, residents can learn to counsel patients to seek legal assistance in the case of an eviction.

Given the complexity of this topic, we suggest three didactic sessions to cover this material: (1) an overview of low-income housing and rapid re-housing; (2) a discussion of the structural causes and consequences of homelessness, as well as strategies for advocating for structural change; and (3) an overview of medical-legal partnerships (Table 1). Programs with less flexibility in their curricula can consider incorporating these topics into systems-based practice education, such as into existing case conferences or during clinical supervision (Table 2).

\section{Goal 4}

The fourth goal for resident education is to exhibit humanism when interacting with patients experiencing homelessness. As illustrated in the aforementioned case study by Braslow and Messac [14], residents may develop cynical attitudes and stigma toward patients experiencing homelessness that can contribute to barriers to care. Patients who are homeless may not establish care in outpatient clinics due to staff who are hostile or dismissive on the basis of a patient's appearance [68]. Some training sites have 
developed educational initiatives designed to improve provider empathy toward patients who are homeless. One interprofessional clinical curriculum incorporated narrative work and reflective practices, which led to improvements in trainee empathy and helper behavior toward patients who were homeless [69].

The Homeless Aligned Patient Care Team (HPACT) of the Veteran Affairs Greater Los Angeles Healthcare System developed and utilizes the "Humanism Pocket Tool" (HPT) to foster humanism and reduce stigma. This tool includes use of "vivid vignettes" to communicate a patient's aspirations and barriers to achieving those aspirations [70]. The HPT encourages residents and team members to use humanistic language to discuss mutual patients. More research is needed to understand resident attitudes and what drives a hesitancy to treat individuals experiencing homelessnessincluding possible concerns about available resources, lack of understanding, or lack of support. We suggest one didactic on humanistic clinical interactions with patients experiencing homelessness that would include how to obtain a narrative history and how to investigate personal subjective reactions to patients such as bias and cynicism.

\section{Additional Educational Options}

We have suggested didactics as a teaching method, but programs may prefer to incorporate these topics into case-based learning or other educational experiences. For instance, a standardized patient case could demonstrate a patient presenting to the ED for the tenth time in several months with a chief complaint of auditory hallucinations and a social history that includes chronic homelessness. Existing case conference series could be modified to include housing status as a consideration for all patients.

An educational exercise that could be easily implemented asks residents to balance a budget as would a patient with housing instability. To illustrate, educators can introduce concepts including the housing wage, minimum wage, and Supplemental Security Income (SSI) benefits. The housing wage is the hourly wage that a worker would need to afford a two-bedroom apartment. In 2018, the housing wage was $\$ 22.10 / \mathrm{h}$ for a two-bedroom rental and $\$ 17.90 / \mathrm{h}$ for one bedroom [71]. In contrast, minimum wages are much lower; in California, for example, the minimum wage is $\$ 11$ per hour, and the federal minimum wage is $\$ 7.25$ per hour. Those who are disabled may also receive SSI benefits. A single adult on SSI would receive a $\$ 771$ federal payment (plus $\$ 10-\$ 200$ in state supplemental payments) per month, which is not enough to live in the national average one-bedroom apartment, costing $\$ 931$ monthly [71]. Through this exercise, residents can better understand the decisions of their patients.

Programs could also consider site visits to housing options for individuals experiencing homelessness (e.g., permanent supportive housing, emergency shelters, encampments and tent cities, safe parking options for people living out of their vehicles), drop-in centers, and legal aid housing programs for experiential learning to help familiarize residents with their patients' social contexts.

Clinical experiences with patients experiencing homelessness would obviously also be valuable to residents when available and could include clinical rotations at homeless clinics or on ACT or other street outreach teams. When these rotations are not available, residents will undoubtedly care for people experiencing homelessness in the ED and inpatient settings. These experiences can be supplemented with clinical supervision that is mindful of the stressors and burden of homelessness.

In conclusion, homelessness affects an individual's physical health, mental well-being, and lifespan. Despite valiant efforts of cities to combat homelessness, it continues to be a public health issue in many areas of the US [2]. Without appropriate training, residents may feel cynical and helpless when caring for patients experiencing homelessness in the ED, hospitals, or outpatient settings. Homelessness-related educational experiences within psychiatry residencies have the potential to empower a new generation of providers to address important health and social inequities.

Acknowledgments The views expressed in this article are those of the authors and do not necessarily reflect the position or policy of the US Department of Veterans Affairs or the US Government. We thank Drs. Ken Wells and Sheryl Kataoka for their helpful discussions.

Funding Information Dr. Ijadi-Maghsoodi receives funding from the 441 National Institute on Drug Abuse of the Nations Institutes of Health under 442 K12DA000357. She also receives funding from the UCLA Pritzker Center for Strengthening Children and Families. Dr. Moore was supported by the VA Office of Academic Affiliations through the National Clinician Scholars Program.

\section{Compliance with Ethical Standards}

We have complied with applicable ethical standards.

Ethical Considerations This manuscript is a commentary on existing research. No original research was conducted. No human subjects were involved in the writing of this paper.

Disclosures On behalf of all authors, the corresponding author states that there is no conflict of interest.

\section{References}

1. Katz MH. Homelessness-challenges and progress. JAMA. 2017;318(23):2293-4.

2. Donovan S, Shinseki EK. Homelessness is a public health issue. Am J Public Health. 2013;103(Suppl 2):S180.

3. Henry MM, Mahathey A, Morrill T et al. The 2018 Annual Homelessness Assessment Report to Congress part 1: point in time 
estimate of homelessness. 2018. https://files.hudexchange.info/ resources/documents/2018-AHAR-Part-1.pdf. Accessed 9/11/2019

4. Burt MR, Aron LY. America's Homeless II: Populations and services. Presentation. Urban Institute, Editor., Urban Institute. Washington, DC; 2000. http://webarchive.urban.org/ UploadedPDF/900344_AmericasHomelessII.pdf. Accessed 9/11/ 2019

5. State of Homelessness. National Alliance to End Homelessness: Washington, DC; 2019. https://endhomelessness.org/ homelessness-in-america/homelessness-statistics/state-ofhomelessness-report/. Accessed 9/11/2019

6. Coletti J. A substantial number of continuums of care in California counted considerably more persons who were homeless in 2019 when compared to their 2017 counts. Homeless and Housing Strategies for California. 2019. https://homelessstrategy.com/asubstantial-number-of-continuums-of-care-in-california-countedconsiderably-more-persons-who-were-homeless-in-2019-whencompared-to-their-2017-counts/. Accessed 9/11/2019

7. Lopez S. Column: He died Sunday on a West L.A. sidewalk. He was homeless. He is part of an epidemic. Los Angeles Times. 2019. https://www.latimes.com/california/story/2019-09-04/homelessdeaths-los-angeles-coroner-record. Accessed 9/11/2019

8. Ridley-Thomas M. Homelessness: deepening, dynamic, and dangerously urgent. 2019. https://ridley-thomas.lacounty.gov. Accessed 9/11/2019

9. National homeless rates decline, but severe housing cost burdens rise. National Low Income Housing Coalition. April 19, 2019. https://nlihc.org/resource/national-homeless-rates-decline-severehousing-cost-burdens-rise. Access 9/12/2019

10. Shanks NJ, Geoge SL, Westlake L, et al. Who are the homeless? Public Health. 1994;108(1):11-9.

11. Tompkins CN, Wright NM, Sheard L, Allgar VL. Associations between migrancy, health and homelessness: a cross-sectional study. Health Soc Care Commun. 2003;11(5):446-52.

12. The Accreditation Council for Graduate Medical Education and The American Board of Psychiatry and Neurology, The Psychiatry Milestone Project. 2015. https://www.acgme.org/ Portals/0/PDFs/Milestones/PsychiatryMilestones.pdf. Accessed 9/11/2019

13. McQuistion HL, Ranz JM, Gillig PM. A survey of american psychiatric residency programs concerning education in homelessness. Acad Psychiatry. 2004;28(2):116-21

14. Braslow JT, Messac L. Medicalization and demedicalization - a gravely disabled homeless man with psychiatric illness. N Engl J Med. 2018;379(20):1885-8.

15. Koegel P, Burnam MA, Farr RK. The prevalence of specific psychiatric disorders among homeless individuals in the inner city of Los Angeles. Arch Gen Psychiatry. 1988;45(12):1085-92.

16. Folsom D, Jeste DV. Schizophrenia in homeless persons: a systematic review of the literature. Acta Psychiatr Scand. 2002;105(6): 404-13.

17. Fazel S, Khosla V, Doll H, Geddes J. The prevalence of mental disorders among the homeless in western countries: systematic review and meta-regression analysis. PLoS Med. 2008;5(12):e225.

18. Desai RA, Liu-Mares W, Dausey DJ, Rosenheck RA. Suicidal ideation and suicide attempts in a sample of homeless people with mental illness. J Nerv Ment Dis. 2003;191(6):365-71.

19. Baggett TP, Hwang SW, O'Connell JJ, et al. Mortality among homeless adults in Boston: shifts in causes of death over a 15year period. JAMA Intern Med. 2013;173(3):189-95.

20. Doran KM, Rahai N, McCormack RP, Milian J, Shelley D, Rotrosen J, et al. Substance use and homelessness among emergency department patients. Drug Alcohol Depend. 2018;188:328-33.

21. Bazari A, Patanwala M, Kaplan LM, Auerswald CL, Kushel MB. 'The thing that really gets me is the future': symptomatology in older homeless adults in the HOPE HOME study. J Pain Symptom Manag. 2018;56(2):195-204.

22. Moulin A, Evans EJ, Xing G, Melnikow J. Substance use, homelessness, mental illness and Medicaid coverage: a set-up for high emergency department utilization. West J Emerg Med. 2018;19(6): 902-6.

23. Patient Protection and Affordable Care Act. 42 USC 18022. 2010. https://www.congress.gov/111/plaws/publ148/PLAW-111publ148. pdf. Accessed 9/12/2019

24. Fact Sheet. The mental health parity act. United States Department of Labor. 2010. https://www.dol.gov/sites/dolgov/files/ebsa/aboutebsa/our-activities/resource-center/fact-sheets/mhpaea.pdf. Accessed 9/12/2019

25. Wenzel SL, Tucker JS, Elliott MN, et al. Prevalence and cooccurrence of violence, substance use and disorder, and HIV risk behavior: a comparison of sheltered and low-income housed women in Los Angeles County. Prev Med. 2004;39(3):617-24.

26. Warf CW, Clark LF, Desai M, et al. Coming of age on the streets: Survival sex among homeless young women in Hollywood. Journal of adolescence. 2013;36(6):1205-1213.

27. Fleisch SB, Kelly AC. Street psychiatry as a community rotation for residents: the UNC homeless support program. Acad Psychiatry. 2014;38(2):246-7.

28. Kaufmann C, Smith M. Interdisciplinary and experiential learning within the homeless community: connecting community work to students and schools. 2017. National Health Care for the Homeless Council Conference Presentation. https://nhchc.confex.com/nhchc/ 2017/webprogram/Session1509.html. Accessed 9/12/2019

29. O'Toole TP, Johnson EE, Aiello R, et al. Tailoring care to vulnerable populations by incorporating social determinants of health: the Veterans Health Administration's "homeless patient aligned care team" program. Prev Chronic Dis. 2016;13:E44.

30. Hansen H, Braslow J, Rohrbaugh RM. From cultural to structural competency-training psychiatry residents to act on social determinants of health and institutional racism. JAMA Psychiatry. 2018;75(2):117-8.

31. Bromage B, Encandela JA, Cranford M, Diaz E, Williamson B, Spell VT, et al. Understanding health disparities through the eyes of community members: a structural competency education intervention. Acad Psychiatry. 2019;43(2):244-7.

32. Clinical Opportunities. UCLA concentration in community and global psychiatry. https://sites.google.com/view/uclacgp/clinicalopportunities. Accessed 9/12/2019

33. NYU psychiatry residency curriculum in cultural, structural and global mental health. NYU Langone Health. https://med.nyu.edu/ psych/education/residency-program/nyu-psychiatry-residencycurriculum-cultural-structural-and-global-mental-health. Accessed 9/12/2019

34. LeMelle S, Arbuckle MR, Ranz JM. Integrating systems-based practice, community psychiatry, and recovery into residency training. Acad Psychiatry. 2013;37(1):35-7.

35. Cultural Psychiatry. UC Davis Department of Psychiatry and Behavioral Sciences. https://health.ucdavis.edu/psychiatry/ specialties/diversity/curriculum.html. Accessed 9/12/2019

36. Stafford A, Wood L. Tackling health disparities for people who are homeless? Start with social determinants. Int J Environ Res Public Health. 2017;14(12):E1535.

37. Thomas B. Homelessness kills: an analysis of the mortality of homeless people in early twenty-first century England. Crisis; 2012. https://www.crisis.org.uk/media/236799/crisis homelessness kills es2012.pdf. Accessed 9/12/2019

38. Khandor E, Mason K, Cowan L, et al. The Street Health Report 2007. Street Health in partnership with the Wellesley Institute. 2007. http://www.streethealth.ca/downloads/the-street-healthreport-2007.pdf. Accessed 9/12/2019 
39. Jego M, Abcaya J, Stefan DE, et al. Improving health care management in primary care for homeless people: a literature review. Int $\mathrm{J}$ Environ Res Public Health. 2018;15(2):E309.

40. Bharel M, Zhang J, O'Connell E, et al. Health care utilization patterns of homeless individuals in Boston: preparing for Medicaid expansion under the Affordable Care Act. Am J Public Health. 2013;103(Suppl 2):S311-7.

41. Gelberg L, Gallagher TC, Anderson RM, et al. Competing priorities as a barrier to medical care among homeless adults in Los Angeles. Am J Public Health. 1997;87(2):217-20.

42. Yoshikawa H, Aber JL, Beardslee WR. The effects of poverty on the mental, emotional, and behavioral health of children and youth: implications for prevention. Am Psychol. 2012;67(4):272-84.

43. Zima BT, Wells KB, Benjamin B, Duan N. Mental health problems among homeless mothers: relationship to service use and child mental health problems. Arch Gen Psychiatry. 1996;53(4):332-8.

44. Jasinski JL, Wesely JK, Mustaine E et al. The experience of violence in the lives of homeless women: a research report. Submitted to the Department of Justice. 2005. https://www.ncjrs.gov/ pdffiles 1/nij/grants/211976.pdf. Accessed 9/12/2019

45. Hayes MA, Zonneville M, Bassuk E. The SHIFT study: final report. American Institutes for Research, the National Center on Family Homelessness. 2010. https://www.air.org/sites/default/files/ SHIFT_Service_and_Housing_Interventions_for_Families_in Transition final report.pdf. Accessed 9/12/2019

46. Robertson MJ, Clark RA, Charlebois ED, Tulsky J, Long HL, Bangsberg DR, et al. HIV seroprevalence among homeless and marginally housed adults in San Francisco. Am J Public Health. 2004;94(7):1207-17.

47. Weiser SD, Dilworth SE, Neilands TB, Cohen J, Bangsberg DR, Riley ED. Gender-specific correlates of sex trade among homeless and marginally housed individuals in San Francisco. J Urban Health. 2006;83(4):736-40.

48. Shultz J, Greer P, Lalota M. HIV seroprevalence and risk behaviors among clients attending a clinic for the homeless in Miami/Dade County, Florida, 1990-1996. Popul Res Policy Rev. 1999;18(4): 357-72.

49. Decker SE, Rosenheck RA, Tsai J, Hoff R, Harpaz-Rotem I. Military sexual assault and homeless women veterans: clinical correlates and treatment preferences. Womens Health Issues. 2013;23(6):e373-80.

50. Hamilton AB, Poza I, Washington DL. "Homelessness and trauma go hand-in-hand": pathways to homelessness among women veterans. Womens Health Issues. 2011;21(4 Suppl):S203-9.

51. Washington DL, Yano EM, McGuire J, Hines V, Lee M, Gelberg L. Risk factors for homelessness among women veterans. J Health Care Poor Underserved. 2010;21(1):82-91.

52. Gamache G, Rosenheck R, Tessler R. Overrepresentation of women veterans among homeless women. Am J Public Health. 2003;93(7):1132-6.

53. Substance Abuse and Mental Health Services Administration. SAMHSA's concept of trauma and guidance for a traumainformed approach. HHS Publication No. (SMA) 14-4884. https://store.samhsa.gov/system/files/sma14-4884.pdf. Accessed 9/12/2019

54. Reeves E. A synthesis of the literature on trauma-informed care. Issues Ment Health Nurs. 2015;36(9):698-709.

55. Street Outreach. Boston Health Care For The Homeless Program. 2014. https://www.bhchp.org/specialized-services/street-outreach. Accessed 9/12/2019
56. Working Party Group on Integrated Behavioral Healthcare. Joint principles: integrating behavioral health care into the patientcentered medical home. Fam Syst Health. 2014;32(2):154-6.

57. Coldwell CM, Bender WS. The effectiveness of assertive community treatment for homeless populations with severe mental illness: a meta-analysis. Am J Psychiatry. 2007;164(3):393-9.

58. Housing Referral Handbook: NYNYIII housing application and referral procedure 2013. The Bronx Health and Housing Consortium. 2013. https://www.health.ny.gov/health_care/ medicaid/program/medicaid_health_homes/docs/bronx consortium_housing_referral_manual.pdf. Accessed 9/12/2019

59. About the homeless initiative. The Los Angeles county homeless initiative. 2019. http://homeless.lacounty.gov/about/. Accessed 9/12/2019

60. Aubry T, Tsemberis S, Adair CE, et al. One-year outcomes of a randomized controlled trial of housing first with ACT in five Canadian cities. Psychiatr Serv. 2015;66(5):463-9.

61. Burt M, Wilkins C, Spellman B et al. Rapid re-housing for homeless families demonstration programs evaluation report part I: how they worked - process evaluation. U.S. Department of Housing and urban Development, Office of Policy Development and Research. 2016. Available at SSRN: https://doi.org/10.2139/ssrn.3055269.

62. Ellen IG. What do we know about housing choice vouchers? Regional Science and Urban Economics. 2018. ISSN 0166-0462. Available at https://doi.org/10.1016/j.regsciurbeco.2018.07.003.

63. Housing opportunities for persons with AIDS fact sheet. In: United States Department of Housing and Urban Development (HUD). HUD Office of HIV/AIDS Housing. 2012. https://files. hudexchange.info/resources/documents/HOPWA-Fact-Sheet.pdf. Accessed 12 Sept 2019.

64. McClure K. Deconcentrating poverty with housing programs. J Am Plan Assoc 2008;74(1):90-99.

65. U.S. Department of Housing and Urban Development-VA Supportive Housing (HUD-VASH) Program. US Department of Veterans Affairs. 2019. https://www.va.gov/homeless/hud-vash. asp. Accessed 9/12/2019

66. $\$ 40$ million in HUD-VASH available to support approximately 5, 000 new vouchers. US Department of Housing and Urban Development. 2019. https://www.hudexchange.info/news/40million-in-hud-vash-available-to-support-approximately-5000new-vouchers/. Accessed 9/12/2019

67. Tobin-Tyler E, Teitelbaum JB. Medical-legal partnership: a powerful tool for public health and health justice. Public Health Rep. 2019;134(2):201-205. https://doi.org/10.1177/ 0033354918824328 .

68. Reuler JB. Health care for the homeless in a national health program. Am J Public Health. 1989;79(8):1033-5.

69. Chrisman-Khawam L, Abdullah N. DhooparA. Teaching healthcare trainees empathy and homelessness IQ through service learning, reflective practice, and altruistic attribution. Int J Psychiatry Med. 2017;52(3):245-54.

70. Soh M, Shaner A, Gelberg L, et al. Using the humanism pocket tool for patients with challenging behaviors. Ann Fam Med. 2018;16(5): 467.

71. Aurand A, Bourret V, Clarke J et al. Out of reach: the high cost of housing. National Low Income Housing Coalition. Washington, DC. 2018. https://nlihc.org/sites/default/files/oor/OOR 2018.pdf. Accessed 9/12/2019

Publisher's Note Springer Nature remains neutral with regard to jurisdictional claims in published maps and institutional affiliations. 